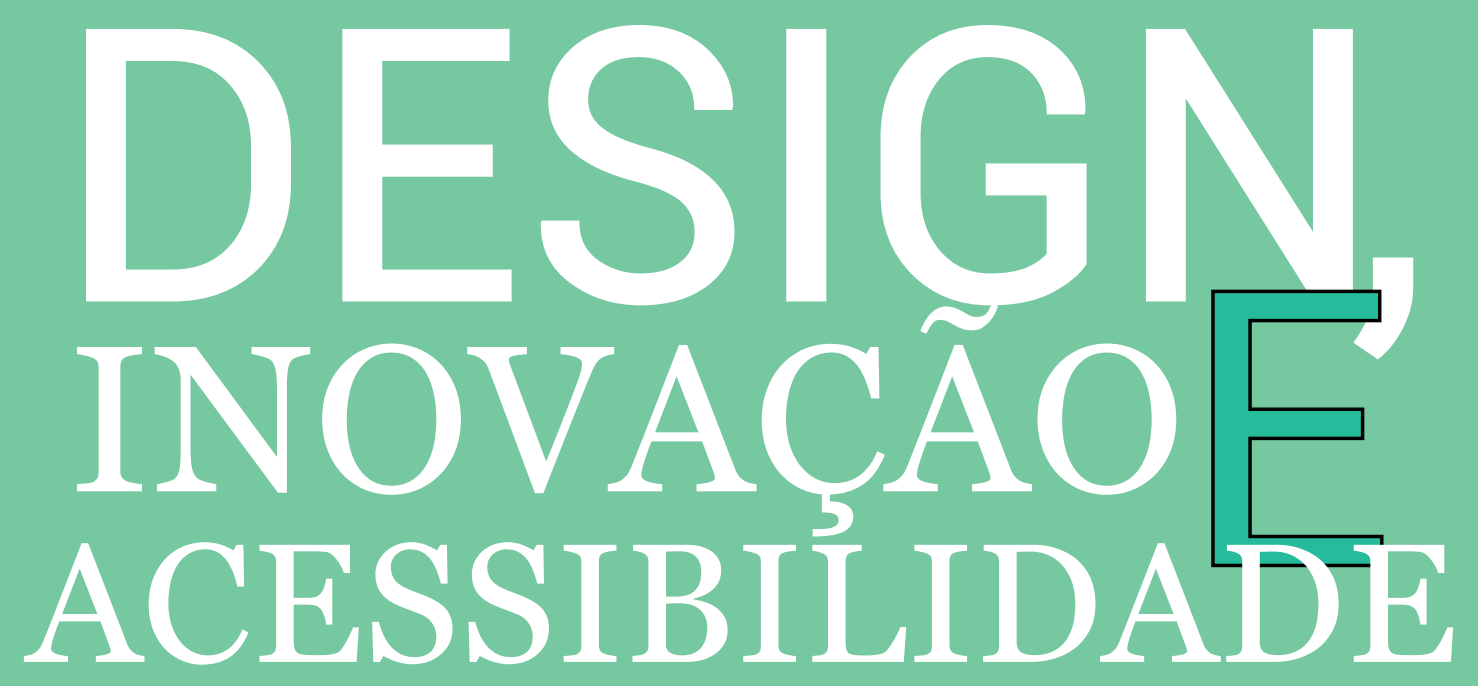




\title{
ERGODESIGN, ECOERGONOMIA, ACESSIBILIDADE E APRENDIZAGEM
}

Francisco Antonio Fialho

\section{Introdução}

\author{
No país de minh'alma há um rio sem mágoas, \\ Um rio cheio de ouro e de tanta harmonia, \\ Que se cuida escutar no marulhar das águas \\ Do sussurro de um beijo a doce melodia. \\ Auta de Souza
}

Onde surgiu o design? Das experiências de Gropius na Bauhaus? No Arts and Crafts inglês? Na terra sem males dos Guaranis? Entre os Ticunas do Amazonas?

Um rio sem mágoas, mas com muitas histórias. Psicólogos, Engenheiros, Médicos, Designers, em cada 
canto desta aldeia chamada mundo, a Ergonomia ensina sem palavras o que é interdisciplinaridade. No início tudo era Engenharia. Aí o espaço passou a pertencer aos Arquitetos e a Forma aos Designers. A fragmentação do saber levou a fragmentação do fazer.

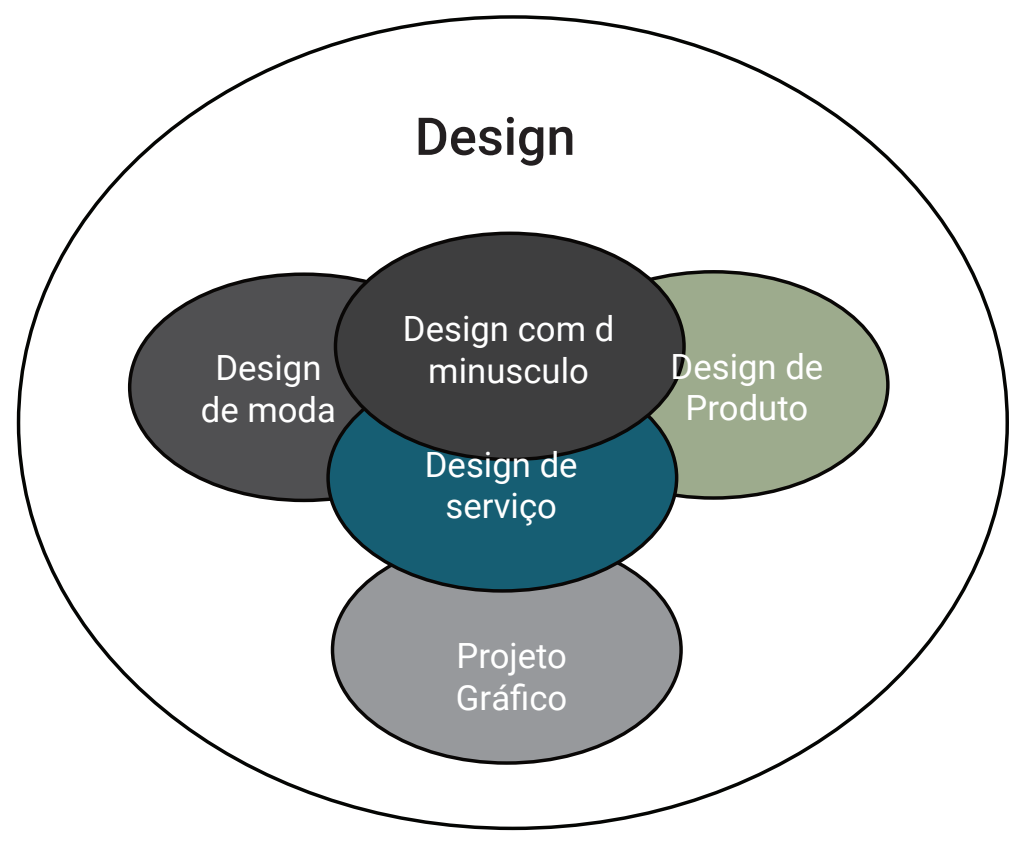

Fig. 1 - Design

Ergonomia vem de muito longe. Ergonomia vem do arco que só Ulisses era capaz de "entesar". Um arco feito sob medida. A tecnologia ao serviço do usuário. O cliente no centro do Mundo.

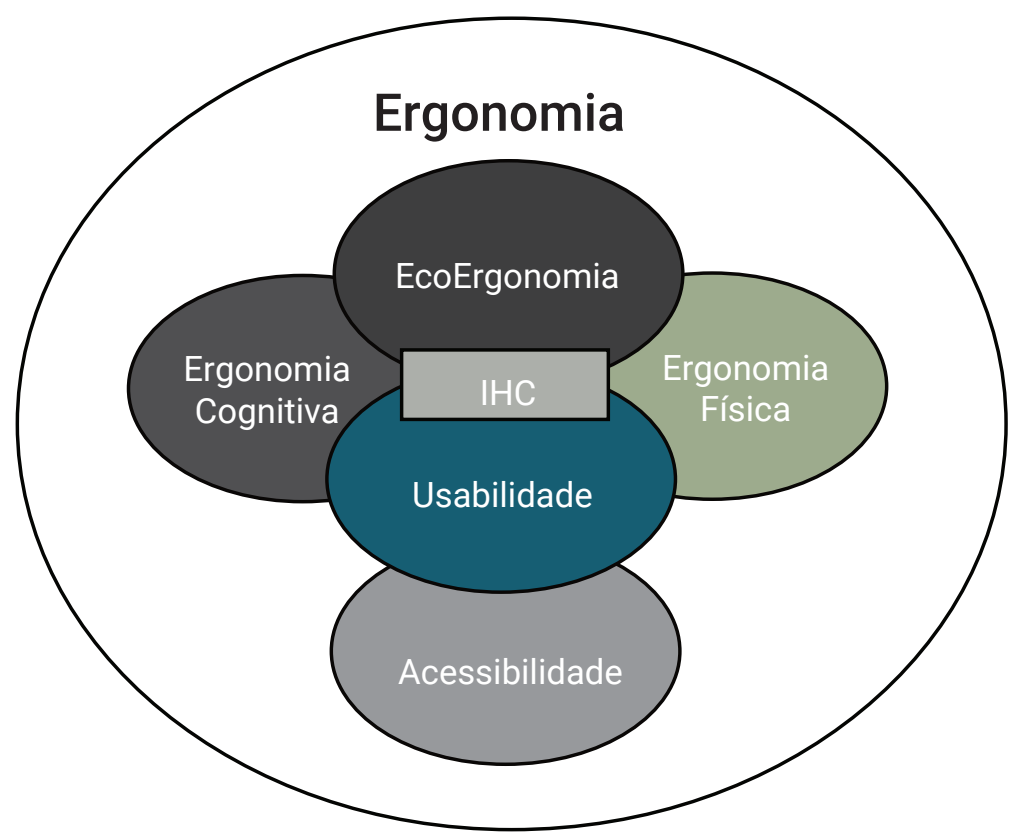

Fig. 2- Ergonomia 
A EcoErgonomia é uma consequência natural que emerge ao se contemplar o entrelaçamento existente entre

1 Les activités mentales. Comprendre, raisonner, trouver des solutions Armand Colin, 1990

2 sychologiedu travail, Presses universitaires de France, Paris, 2002

4 Wisner A., 1991, « Cognitive Psychology and Anthropology ", (collected papers), Conservatoire national des arts et métiers, Paris, mimeo Volume I.
3 M. de Montmollin (1986),

L'ergonomie, Paris, La Découverte

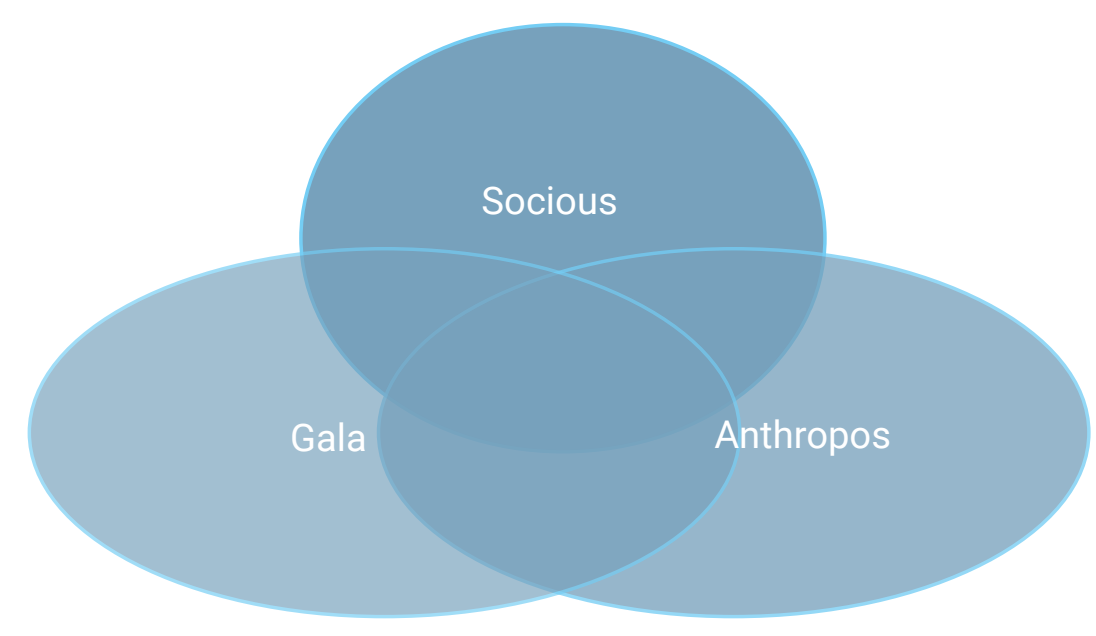

Fig. 3 - Ecosofia. Fonte: Guattari
Enquanto a técnica privilegia o Socius e objetiva o Lucro e a Ergonomia, clássica, se centra no Anthopos, cujo objetivo é sempre, uma melhor Qualidade de Vida; a Ecoergonomia pretende um equilíbrio entre estas três dimensões, reconhecendo Gaia, a mãe Terra, como um autor que precisa ser considerado. Como conciliar preservação da natureza, conforto do ser humano e lucro?

Hoje falamos em Design de Experiência; Design de Interação; Design centrado no usuário. Muitas denominações para se falar do que resulta do encontro destas duas disciplinas:

Ergonomia e Design.

Só para situarmos nosso pensamento neste vasto campo, pertencemos a velha Escola Francesa de Ergonomia ilustrada por nomes como Jean François Richard ${ }^{\mathbf{1}}$, Christian Guillevic ${ }^{\mathbf{2}}$, Maurice de Montmollin ${ }^{3}$ e não poderíamos deixar de citar aquele que é considerado um dos pais da Ergonomia no Brasil, Alain Wisner ${ }^{4}$.

Com base nestes autores e em pesquisas com nossos alunos de Ergonomia nos Programas de Pós-Graduação em Engenharia de Produção e Engenharia do conhecimento, publicamos dezenas de artigos e os seguintes livros:

Inspirados em Jean François Richard, os seguintes trabalhos em Ergonomia Cognitiva (disciplina que ministramos por vários anos aos alunos de Design da Universidade Federal de Santa Catarina). AErgonomia Cognitiva de Richard tem forte influência de Jean Piaget: 
- Psicologia das Atividades Mentais. Florianópolis: Editora Insular, 2011, v.100o. p.344.

- Ciências da Cognição. Florianópolis: Editora Insular, 2001, v.100o. p.263.

Junto com o Professor Neri dos Santos, aluno de Alain Wisner, publicamos outros dois volumes:

- Manual de Análise Ergonômica do Trabalho. Curitiba: Gênesis Editora, 1995, v.200o, p.283. (Este livro teve sua segunda edição em 1997, v. 1000, p.316).

- Antropotecnologia: a Ergonomia das Organizações. Curitiba: Genesis, 1997, v.10oo. p.320. (Este contou com a colaboração de Roane Proença, professora de nutrição e Carlos Ramirez Righi, designer)

Em alguns países Ergonomia se resume a estabelecer as regras (Nomos) que devem ser seguidas no trabalho (Ergon). Para nós Ergonomia é muito mais do que isso, é transformar o trabalho sofrimento (ponein) em trabalho prazer (ergon).

Considerando que o ser humano nunca está satisfeito, que é da sua natureza o querer sempre mais, cabe a nós Ergonomistas, como o Dom Quixote de La Mancha, de Miguel de Cervantes, buscar o impossível na tentativa de satisfazê-lo.

Ergonomia não é só técnica, é paixão.

\section{Ergodesign}

5 Normose - a patologia da normalidade, ed. Vozes, Roberto Crema, Jean-Yves Leloup, Pierre Weil; org. Suzana Beiro
Nenhum poder, um pouco de saber, um pouco de sabedoria, e o máximo de sabor possível.

(Roland Barthes)

O estético atrelado a subjetividade humana e o funcional a remeter às questões de técnica remodelaram o conceito do que seria Design. A estética, admirada na Bauhaus e negada em Ulm, ressuscita, quando se incorpora Ergonomia ao Design, produzindo um Design com saber e com sabor.

Ergonomia é a "ciência das interfaces" e o conceito de usabilidade é inerente ao "de adaptar o trabalho ao homem e não o contrário”. Usabilidade não serve apenas para o diagnóstico e a solução de problemas em interfaces computadorizadas, conhecidos pela sigla IHC (Interface Humano Computador), mas para todo e qualquer tipo de interface.
Conter, cortar, comprimir são tarefas que podem ser realizadas por artefatos. O Ergodesign cuida das interfaces entre estes artefatos e os seus usuários. Por isso que tanto as pontas de lanças usadas pelos caçadores coletores como o mouse têm formas semelhantes, compatíveis com o ato de manipular estes objetos.

Mas quem são estes usuários?

Um design inclusivo entende que seres humanos pertencem a diferentes grupos. Ciências como a antropometria e a biomecânica; a psicologia; a sociologia; a antropologia, dentre muitas outras, auxiliam o Ergonomista a identificar a variedade.

Temos altos e baixos, falantes e não falantes, ouvintes e surdos, cegos, pessoas de QI abaixo ou acima da média. Aliás, não gostamos de médias em Ergonomia.

A Ergonomia Ideal se ajusta a cada indivíduo, Down, Autista, Cadeirante; até aos que sofrem de nor$\operatorname{mose}^{\mathbf{5}}$ (como ensinam Pierre Weil, Roberto Crema e Jean Yves Leloup).

Normose se refere a normas, crenças e valores sociais que causam angústia e podem ser fatais, em 
outras palavras "comportamentos normais de uma sociedade que causam sofrimento e morte". Ebnfrentar a normose é uma das tarefas mais importantes a ser realizada pelos Ergonomistas.

Nas minhas experiências iniciais ficava horrorizado ao assistir trabalhadores desossando frangos em serras sem o uso de luvas, ou usando britadeiras sem proteção para os olhos. É comum justificar a manutenção de um comportamento não saudável por ser normal, algo que «todo mundo faz».

A ergonomia é uma ciência que estuda o comportamento e reações do homem em relação ao seu trabalho, à máquina que ele opera e ao ambiente da estação de trabalho. A pesquisa ergonômica objetiva adaptar o trabalho ou a máquina às capacidades humanas, de modo a facilitar o trabalho e garantir máquinas amigáveis. (GRAND-

JEAN, E.; 1969)

Ambientes e estações de trabalho, máquinas, equipamentos, que integram a ergonomia ao design contribuem para a minimização dos acidentes de trabalho, melhoram a qualidade de vida, promovem o bem-estar e, consequentemente, otimizam o desempenho dos produtos.

Quando presidente da ABERGO em 1997, participamos, em Tampera, na Finlândia, de um encon- tro de uma comissão da IEA (International Ergonomics Association) que coletava definições para Ergonomia. Na época já se somavam mais de mil. Melhor falar em "infinições" (em vez de "dar fim” é necessário manter aberto o diálogo).

O designer de hoje deve promover a união da linguagem estética e da funcional. Precisamos de produtos criativos, lúdicos e funcionais, projetados de acordo com propósitos e conceitos que permitem não apenas um custo acessível, mas sobretudo a fácil compreensão e utilização por parte do usuário.

Blaich (1997) discute a necessidade do esclarecimento do que os designers entendem pelo termo "ergonomia", como enxergam a sua importância e como vislumbram as perspectivas para o seu desenvolvimento. Conversando ou vendo vídeos de designers percebemos que há uma compreensão limitada, restrita ao que chamamos de Ergonomia Física. Como sempre temos um usuário envolvido com um objeto, a ergonomia precisa ser compreendida como uma parte integral do design.

Os produtos são cada vez mais complexos e a Ergonomia Cognitiva não pode ficar esquecida. Ela deve estar presente em todo processo de desenvolvimento do design (projeto) de um produto.

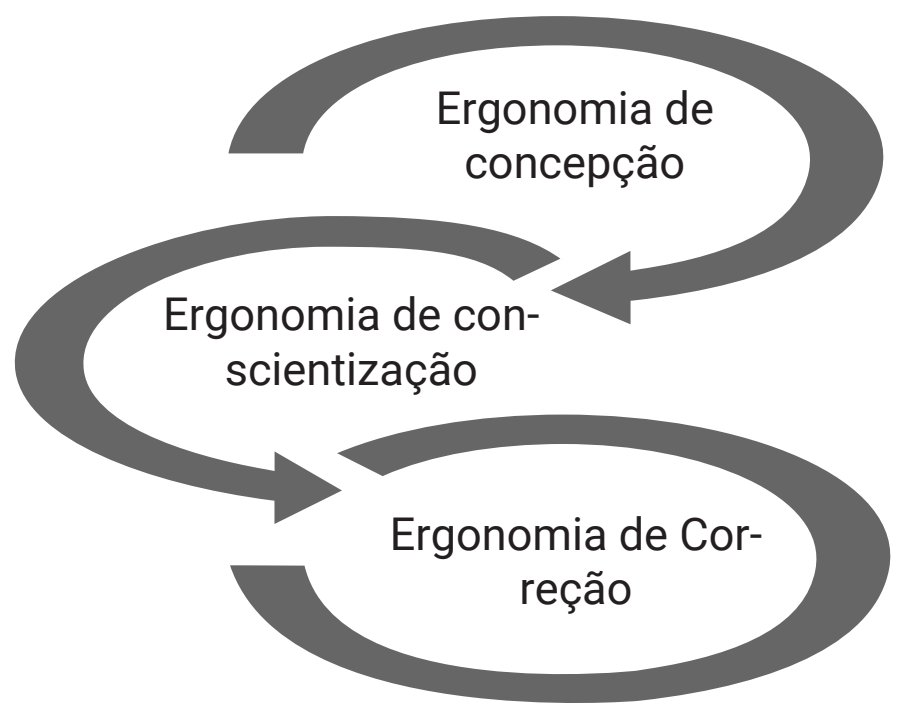

Fig. 4 - Conceito de Ergonomia 
6 O Institut National de Recherche en Informatique et en Automatique (INRIA) é uma organização pública francesa de carácter científico e tecnológico criada em janeiro d 1967. Realiza pesquisas nas áreas de informática e automação.
Em um encontro Brasil França na Universidade Federal de Santa Catarina (workshop acontecido em 1996) estávamos ciceroneando Jean François Richard da Paris VIII e Dominique Scapin do INRIA (Institut National de Recherche en Informatique et en Automatique da França). Discutíamos a importância de uma Ergonomia de Concepção e não meramente uma Ergonomia de Correção.

Somos geralmente chamados para retrabalhos que resultam da não inclusão da Ergonomia desde as fases iniciais de um projeto. A luta dos ergonomistas deveria ser por uma Ergonomia de Conscientização que convença aos Designer da importância de incorporar a Ergonomia a sua prática.
Scapin e Christian Bastien, do INRIA ${ }^{\mathbf{6}}$, desenvolveram os "Critérios Ergonômicos", um conjunto de qualidades ergonômicas que as interfaces humanocomputador deveriam apresentar. O conjunto é composto por 8 critérios ergonômicos principais que se subdividem em 18 subcritérios e critérios elementares.

Um critério sempre lembrado como importante dentro da Escola Francesa, é a questão da Regulação da Atividade. Em tempos modernos de Chaplin é o supervisor quem controla o trabalho ao acelerar ou retardar a linha de produção. Ergonomia é autorregulação, para que cada trabalhador possa ajustar o seu fazer as suas características.

Um critério descrito por Scapin é a “condução” que se refere aos meios disponíveis para aconselhar, orientar, informar, e conduzir o usuário na interação com o computador (mensagens, alarmes, rótulos, etc.). Quatro subcritérios participam da "condução": Presteza, Agrupamento, distinção entre itens, Feedback imediato e Legibilidade.

\begin{tabular}{|c|c|c|}
\hline Palestrantes & Instituições & Artigos \\
\hline Neri dos Santos & UFSC/Brasil & "Uma introdução à modelagem ecoergonômica". \\
\hline $\begin{array}{l}\text { Jean-François } \\
\text { Richard }\end{array}$ & $\begin{array}{l}\text { Paris VIII } \\
\text { França }\end{array}$ & $\begin{array}{l}\text { "Ferramentas para analisar e melhorar a compreensão das tarefas } \\
\text { técnicas". }\end{array}$ \\
\hline Dominique Scapin & INRIA/França & "Inspeção ergonômica de interfaces e critérios ergonômicos". \\
\hline Jean-Marc Robert & EPM/Canadá & $\begin{array}{l}\text { "Questões Relacionadas a Tarefa no Projeto da Interação Homem- } \\
\text { Computador". }\end{array}$ \\
\hline Françoise Detienne & INRIA/França & "A concepção e a reutilização de software: abordagem ergonômica". \\
\hline Water de Abreu Cybis & $\begin{array}{l}\text { UFSC/La- } \\
\text { bIUtil/Brasil }\end{array}$ & $\begin{array}{l}\text { "Modelo de objetos de interação abstratos ergonômicos: desen- } \\
\text { volvimento e perspectivas". }\end{array}$ \\
\hline Francisco Fialho & UFSC/Brasil & "Organizações, velhas metáforas e novas ideias". \\
\hline $\begin{array}{l}\text { Lia Buarque Magal- } \\
\text { hães }\end{array}$ & $\begin{array}{l}\text { PPGEP-RS/ } \\
\text { Brasil }\end{array}$ & "Aspectos perceptivos da interação homem-computador". \\
\hline Raul Waslawick & UFSC/Brasil & "Agentes autônomos e teoria de equilibração cognitiva". \\
\hline Leonor Scliar-Cabral & UFSC/Brasil & “Acesso Lexical”. \\
\hline
\end{tabular}


Os artigos que foram apresentados no workshop Brasil França citado estão listados na tab ela abaixo:

Chapanis (1965) afirma que o termo "design" é essencial para a definição do significado de ergodesign, porque o mesmo promove uma separação em relação a disciplinas puramente acadêmicas como antropologia, fisiologia e psicologia.

"Nós estudamos as pessoas, mas nós as estudamos não por querer meramente adicionar à nossa coleção de informações básicas. Estuda-se as pessoas em circunstâncias especiais porque nosso objetivo é aplicar o que sabemos ou o que descobrimos ao design de coisas práticas - de coisas que temos que fazer ou temos que usar por causa de nossas ocupações, ou coisas que queremos fazer ou queremos usar por causa de nossas inclinações" (CHAPANIS, 1965).

Resumindo, podemos dizer que o ErgoDesign se confunde com o conceito que temos do que seria um "bom design". Não se compreende mais, em um momento em que se caminha cada vez mais em direção a um Design Centrado no Usuário, a possibilidade de se esquecer da Ergonomia em todas as fases de projetação.

\section{Ecoergonomia}

Os livros sabem de cor milhares de poemas. Que memória! (Paulo Leminski)

A EcoErgonomia consiste em se incorporar questões relativas ao Design a todas as questões. Não se trata apenas em um Design Centrado no Ser Humano, mas em um Design que estende esta humanidade a todas as coisas animadas ou inanimadas.

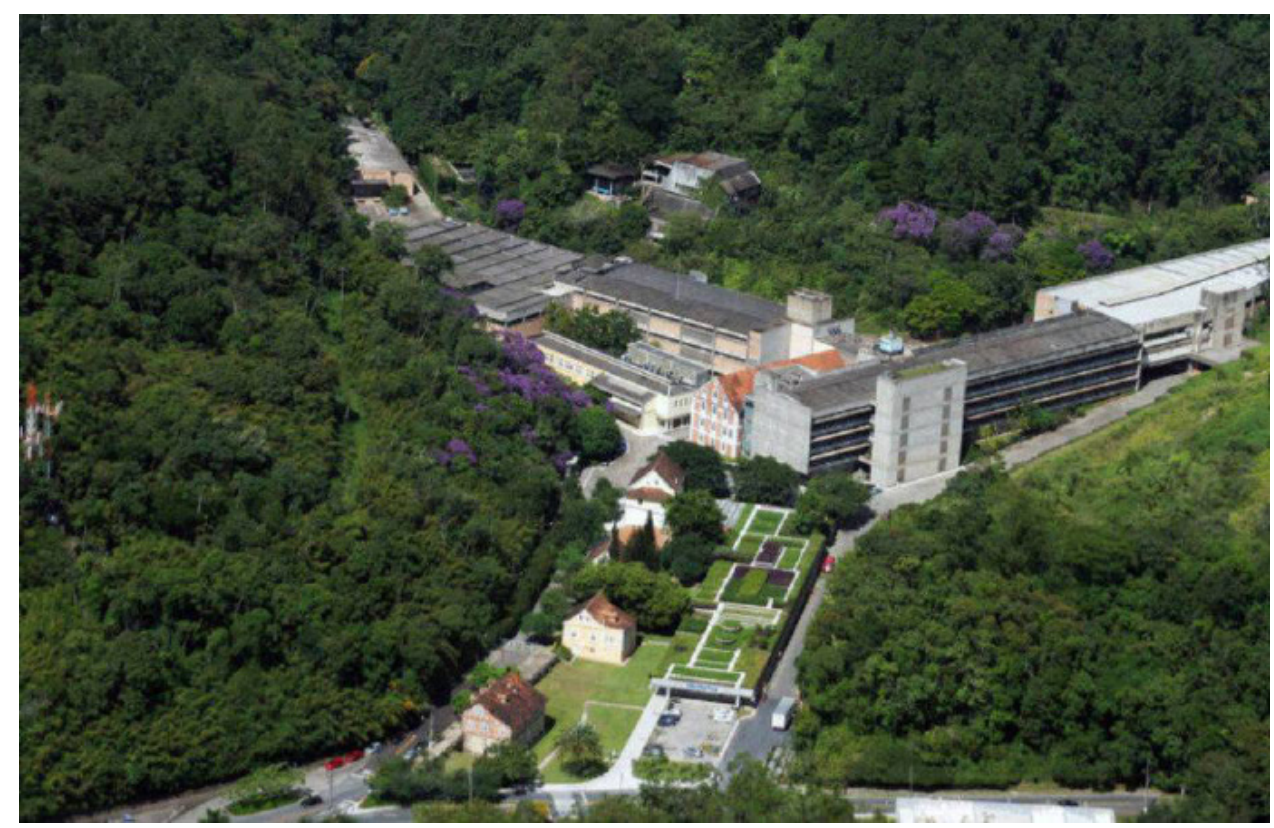

Fig. 5 - Vista da Hering de Blumenau

Não basta que eu, cognitivamente, saiba da importância da árvore para um dado ecossistema. Se eu não estiver envolvido, se eu não "amar" a árvore, não vou levá-la em conta nos meus projetos.

Alguns exemplos interessantes podem ser men- cionados. Quando olhamos o prédio da Hering de Blumenau percebemos a preocupação com a preservação da natureza. A sede da Cia. Hering em Blumenau ocupa uma área construída de 39.663 metros quadrados. Em todas as suas unidades em 


\section{ELETROSUL e}

FURNAS são empresas de energia elétrica que, nas décadas de 70,80 e 90 eram responsáveis pela geração e transmissão de energia nas Regiões Sul e Sudeste do Brasil, respectivamente.

8 É o conceito de uma realidade subjacente unificada da qual tudo emerge e para o qual tudo retorna. A ideia foi popularizada no século 20 pelo psicanalista suíço Carl Gustav Jung, embora o termo pode ser rastreado até escolásticos como Duns Scotus.
Santa Catarina, a empresa mantém 8,5 milhões de metros quadrados de áreas verdes preservadas e 750.000 metros quadrados de reserva legal.

De onde vem a preocupação de Bruno e Hermann Hering com a preservação do meio ambiente? Estamos falando de fins do século XIX quando as empresas anunciavam com orgulho a compra de hectares de araucárias para serem derrubadas e transformadas em papel.

Na década de 1980 fui responsável pelo projeto do Despacho de Carga da ELETROSUL 7 em Curitiba.

Meus arquitetos tiveram todo o cuidado em preservar um bosque que existia no terreno.

Na semana seguinte ao envio do projeto para a obra o engenheiro chefe da mesma me telefonou e disse: -"Sabe, Fialho, aquele bosque... deu uma ventania (leia-se trator) que derrubou todas as árvores”. Lembram da necessidade de uma Ergonomia de Conscientização?

Antes disso, quando comecei a minha vida como engenheiro, na década de 1970, o comportamento de um engenheiro americano em FURNAS era motivo de chacota. Ele ficava medindo mesas e cadeiras e ninguém entendia que ele estava fazendo Ergonomia.

A EcoErgonomia hoje se encontra na mesma situação que a Ergonomia Física nas décadas de 1970 e 1980. Uma completa desconhecida.

Somos uma sociedade complexa. Não evoluímos dentro do meio ambiente, evoluímos dentro de uma cultura. Esta cultura inclui seres humanos e agregados, como cães, gatos, cavalos, bois, lhamas e até mesmo os pássaros e peixes que se alimentam de nosso "estar no mundo". Um Design verdadeiramente inclusivo deveria pensar, por exemplo, nos cães labradores guiando seres humanos cegos em espaços que foram pensados sem incluí-los.

O meio ambiente também deve ser entendido como Unus Mundus ${ }^{\mathbf{8}}$, um ser vivo, que precisa ser entendido, respeitado e auxiliado em seu caminho pelas estadas do tempo.

Como seria um ErgoDesign Ecoergonômico? Com certeza seria um Design que além de acessibilidade e usabilidade incorporaria a sustentabilidade. O respeito ao meio ambiente evitando-se o desperdício.

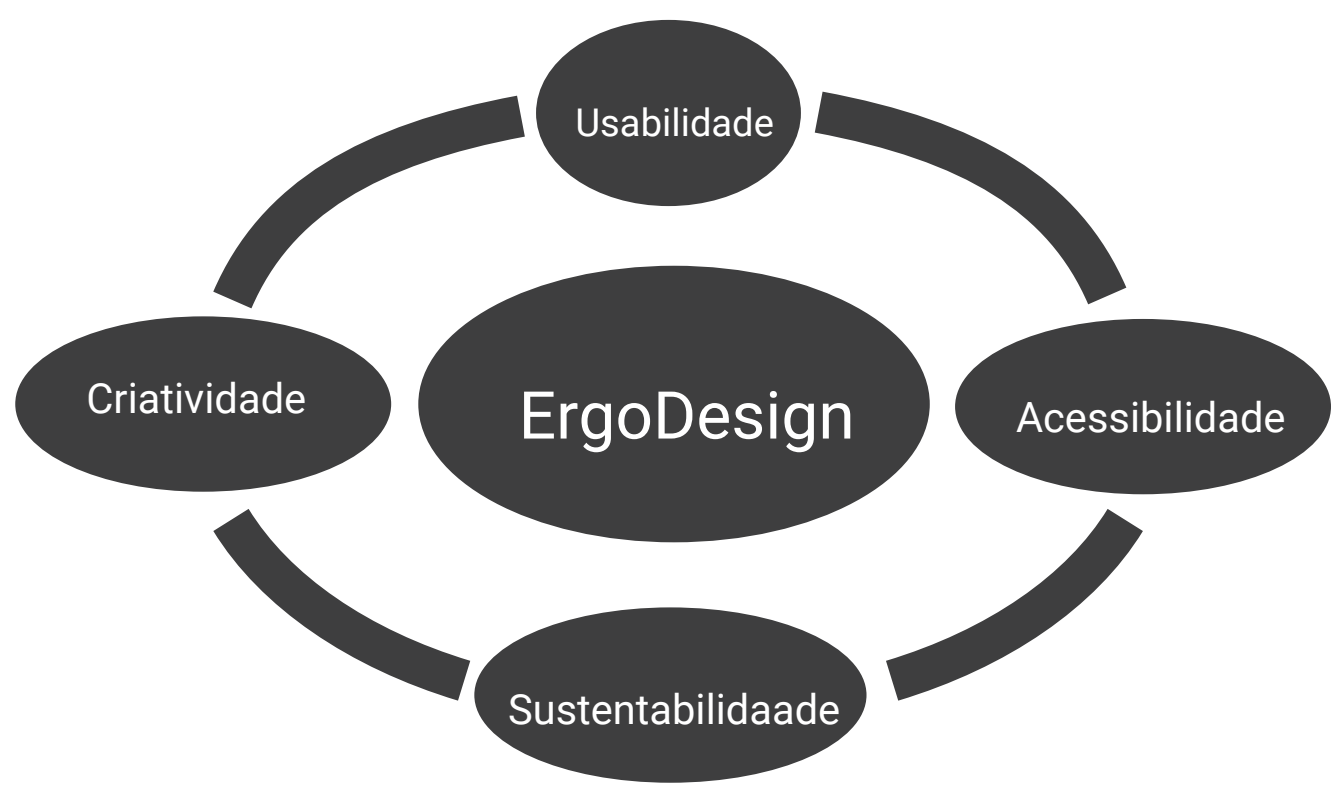

Fig. 6 - EgoDesign Ecoergonômico 
A preocupação com a vida de produtos, serviços e experiências. Projeto que se estenderia por toda a vida do produto, serviço ou experiência, do berço ao túmulo.

A melhor forma de se entender um conceito é for- necer exemplos (Ergonomia Cognitiva). Analogias e metáforas, cuidadosamente escolhidas para evitar confusões, dissonâncias.

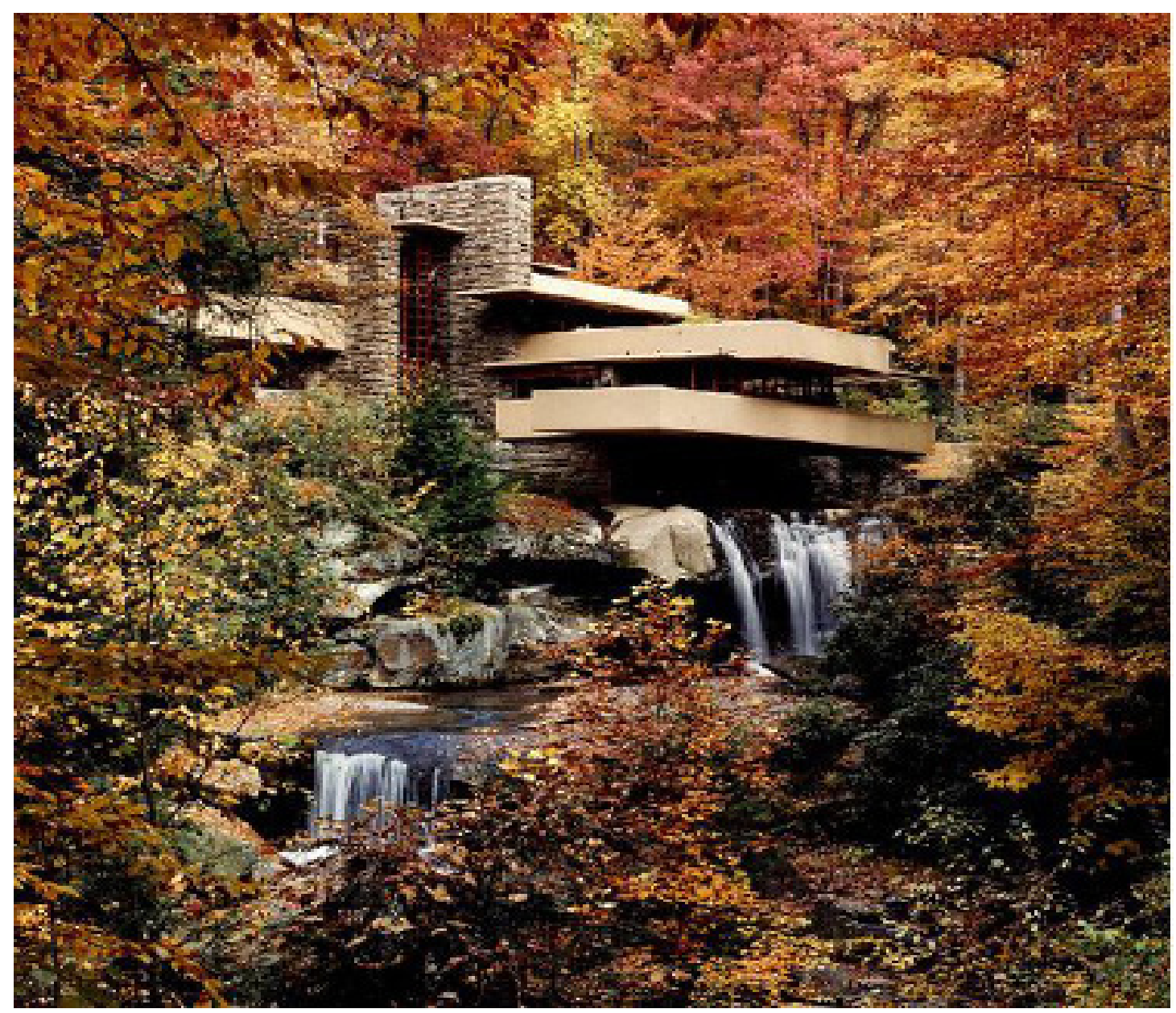

Fig. 7 - Casa da Cascata

9 Wright, famoso arquiteto americano, acreditava no design de estruturas em harmonia com a humanidade e seu entorno. Uma Arquitetura Orgânica.
Piaget fala da superioridade do sim em relação ao não. Mesmo quando podemos concluir, fazemos uma perguntinha a mais, só para ter certeza. Um exemplo quase perfeito de Design EcoErgonômico é a arquitetura orgânica, como a expressa na casa da cascata de Frank Lloyd Wright ${ }^{9}$. Observe a preocupação em se integrar ao entorno.
Um exemplo no Brasil é o projeto original da Universidade Federal da Amazônia, infelizmente não respeitado em obras posteriores.

A máquina conexionista funciona como um computador paralelo formado por bilhões de neurônios (por enquanto as máquinas estão na granularidade dos milhões). A rede aprende com o seu operar, ajustando as suas sinapses até encontrar respostas 
10 CUNHA FILHO,

José Leão: A

certeza da incerteza

educa. http://

www.humanitates.

ucb.br/3/certeza.

htmseu entorno. Uma

Arquitetura Orgânica.

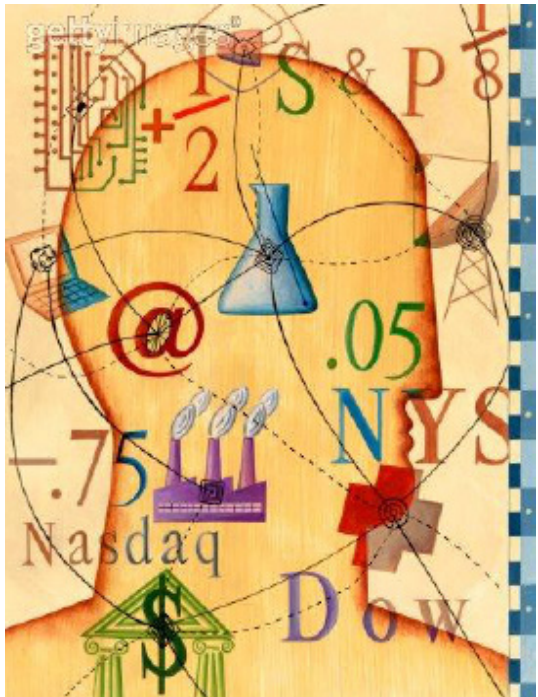

Fig. 8 - A máquina conexionista

adequadas.

A riqueza cognitiva se dá nas interações. Somos redes dentro de redes, em processo de aprendizagem.

\section{Acessibilidade e Aprendizagem}

O professor não ensina, mas arranja modos de a própria criança descobrir. Cria situaçõesproblemas. (Jean Piaget)

Maturana e Varela estabeleceram a teoria da au- topoiesis, que se sustenta na ideia de que seres vivos se autofabricam. Enquanto as máquinas alopoiéticas produzem "para fora, para o mundo", as máquinas autopoiéticas produzem a si mesmas.

Somos os designers de nós mesmos. Como adaptar o mundo a você e não você ao mundo? Na verdade precisamos de infinitos mundos, um para cada ser que compartilha conosco um mesmo ecossistema. Maturana nos traz duas contribuições importantes. Em primeiro lugar, rejeita a concepção de inteligência como atributo individual independente. Inteligência não é uma capacidade individual, mas relacional. Nossa ação, na malha das rela-

11 BROWN, Tim. Design

Thinkingentorno.

Uma

Arquitetura Orgânica.

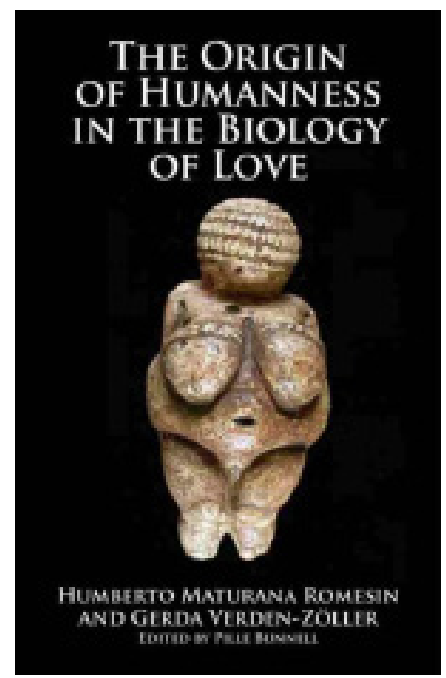

Fig. 9 
ções sociais, revela nosso comportamento inteligente. O comportamento inteligente é contextual, manifesta-se no contexto. O comportamento inteligente manifesta-se na relação com o outro - "domínio consensual" - e com o meio ambiente - "adaptação ontogênica”. Realiza-se, portanto, através da flexibilidade e da consensualidade ${ }^{10}$ :

Somos dentro de uma cultura. Estamos todos conectados como no filme AVATAR de James Cameron. Maturana nos fala da necessidade de um "acoplamento amoroso" em sua "Biologia do Amor”. Na teoria da autopoiesis o importante não é a representação, mas a ação.

Conhecer é o mesmo que criar. Aprender é tomar consciência dos mundos novos que estamos construindo pelo nosso operar.

Piaget já dizia que sua teoria era uma gestaltkreis. Não apenas um "todo", mas um “todo" sobre o qual se opera para obter um resultado. Conhecer, na visõ autopoiética, é um processo e não uma “coisa”.

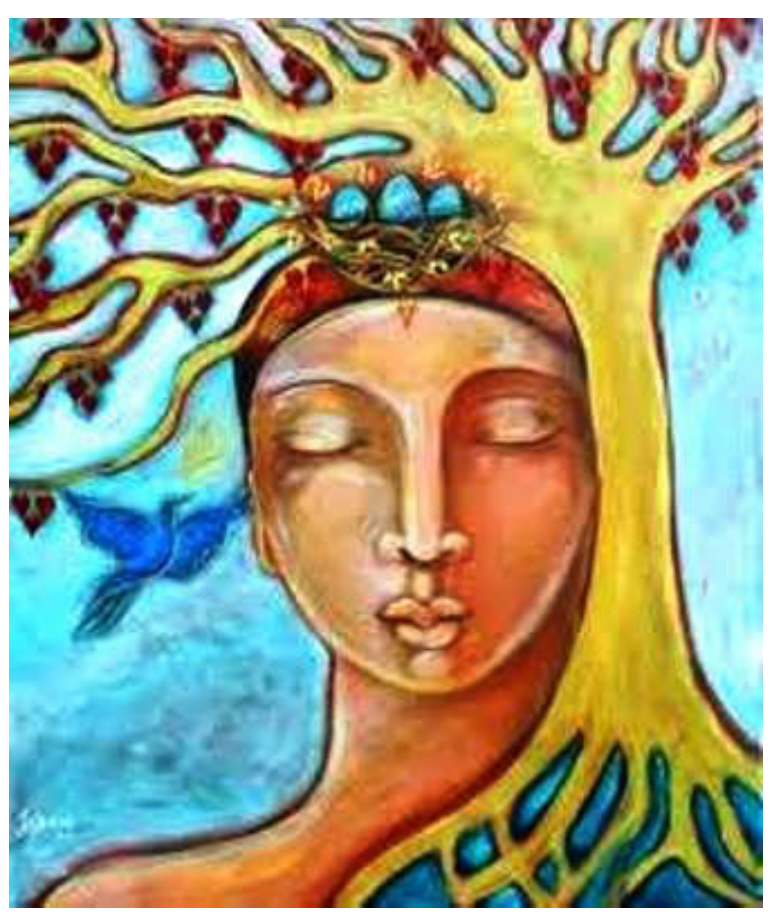

Fig. 10- A máquina autopoiética http://cristianegantus.blogspot.com.br/2012/10/autopoiese-cultura-e-sociedade-por.html

O Design Thinking fala da possibilidade de um "Design do Futuro"11. O universo é uma rede hipertextual de significados quântica e complexa. Somos uma rede dentro desta rede, constantemente nos modificando e, por conseguinte, modificando as redes: "os todos" dos quais somos parte.
Conhecer não é individual, mas coletivo. Estamos em contínua interação com os outros fora de nós e os outros dentro de nós.

A máquina autopoiética não tem entradas e nem saídas. Funciona por meio de perturbações internas. 
O Design do Futuro é um UX Design, de experiências que levem em direção à Aprendizagem

Para Maturana, o termo "autopoiese" significa o "centro da dinâmica constitutiva dos seres vivos". Seres vivos são ao mesmo tempo autônomos e dependentes. Trata-se, pois, de um paradoxo.

Nossas fomes internas nos forçam a nos abrir para o mundo de forma intencional, em busca de algo que sacie estas fomes. Trata-se de uma máquina "ativa" e não "reativa”. Devemos trocar o caminhar cego "sem projeto" por um caminhar consciente, "desenhado para que se atinja a felicidade, seja isso o que for".

\section{Anamaria de Moraes, patrona do Ergodesign}

Não sou nada. Nunca serei nada.

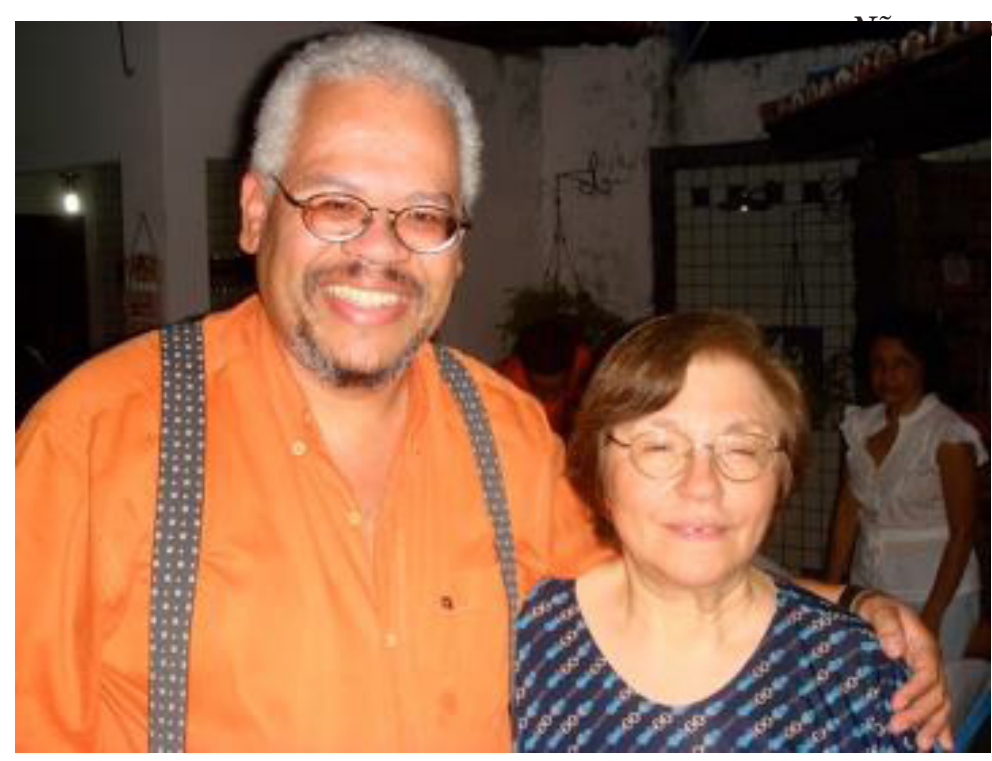
querer ser nada.

Fig. 10- Marcelo Soares e Anamaria de Moraes.

À parte isso, tenho em mim todos os sonhos do mundo.

(Fernando Pessoa)

Como falar em Ergodesign e não citar a nossa querida amiga Anamaria de Moraes (10 de maio de 1942 a fevereiro de 2012).

Estávamos no 180 Congresso Internacional de Ergonomia em 2012, o primeiro a ocorrer no Brasil, em Recife, terra de Marcelo Soares, promotor do evento, quando choramos a "morte ergon" de nossa eterna mestra Anamaria, ocorrida durante o sono, no quarto do mesmo hotel em que nos hospedamos.
Falamos em "Morte Ergon" porque se ela pudesse escolher onde morrer, não hesitaria em afirmar que deveria ser em algum evento envolvendo Ergonomia.

Anamaria dedicou a sua vida a Ergonomia em geral e ao Ergodesign em particular. Estivemos com ela um dia antes de sua morte. Presenciamos sua felicidade, sua alegria por presenciar o evento máximo da Ergonomia sendo realizado em seu país. Ela saltitava. Seus olhinhos brilhavam. Ela irradiava vida. Ela não morreu, virou estrela.

Marcelo nós conhecemos quando fomos presidente da ABERGO. Em 1997 um brasileiro ganhava o prêmio de melhor tese na Europa. Uma tese em Ergonomia. O nosso Marcelo. 
12 TEILHARD DE CHARDIN, P. 1959. L'Avenir de L'Homme. Paris, Seuil, 406 p. TEILHARD DE CHARDIN, P. 1971. El fenomeno humano. Barcelona, Taurus, 383 p.Uma Arquitetura Orgânica.
Antes de nossa breve passagem pela ABERGO, Anamaria (1994 -1995) esteve à frente da Associação Brasileira de Ergonomia, que ajudou a fundar em 1983.

Um dos muitos livros de Anamaria foi "Ergodesign - Produtos e processos" publicado em conjunto com Bianka Capucci Frisoni.

Patrocinou ou esteve presente em todos os congressos de Ergodesign \& USICH de 2001 a 2005: Rio de Janeiro (RJ); 2006: Baurú (SP); 2007: Balneário Camboriú (SC); 2008: São Luís (MA); 2009: Curitiba (PR); 2010: Rio de Janeiro (RJ); 2011: Manaus. O céu com certeza se tornou melhor com a sua chegada;

Segundo Wenger (1998, p. 54) “o significado não existe dentro de nós nem no mundo exterior, mas na relação dinâmica da vivência no mundo”. O Ergodesign é apenas um dos muitos legados deixados por Anamaria de Moraes. O primeiro mestrado em Design da América Latina aconteceu em 1994 graças a sua poderosa influência.

A linguagem do ego, simbólica e lógica, das verdades incontestes, perde espaço para a linguagem da alma cheia das incertezas de que fala Edgar Morin. A primeira quer se impor pela retórica, a segunda só deseja compartilhar lembranças.

Era assim que Anamaria falava, com a alma. Ela não fazia Ergonomia; ela amava Ergonomia. Era um vendaval que arrastava a tudo e a todos.

Hoje seus orientandos e amigos, em particular a sua eterna escudeira, Lia Buarque, continuam a propagar a Ergonomia pelos sete cantos.

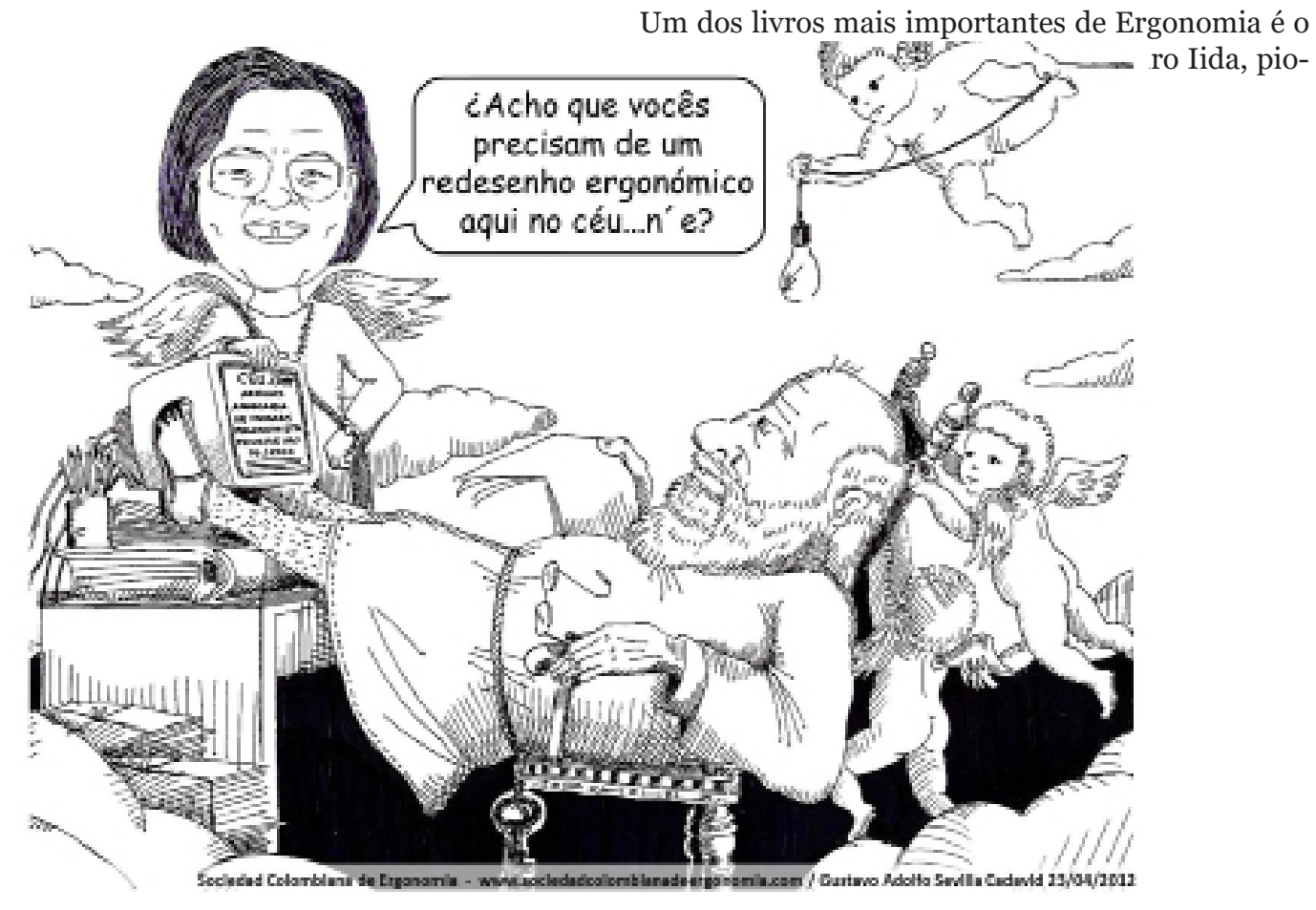

Fig. 11- Arte: Gustavo Cadavid, Colômbia. Cedido gentilmente por Marcelo Soares

neira na área, que conta com a coautoria da Lia em sua terceira edição.

As minhas lembranças de Anamaria são: um enorme sorriso; uma energia inquebrantável e uma fé inabalável na capacidade da Ergonomia de transformar o mundo. 
Com certeza que o céu, depois que Anamaria partiu para nele viver, se tornou um lugar bem melhor.

\section{Até breve, amiga querida.}

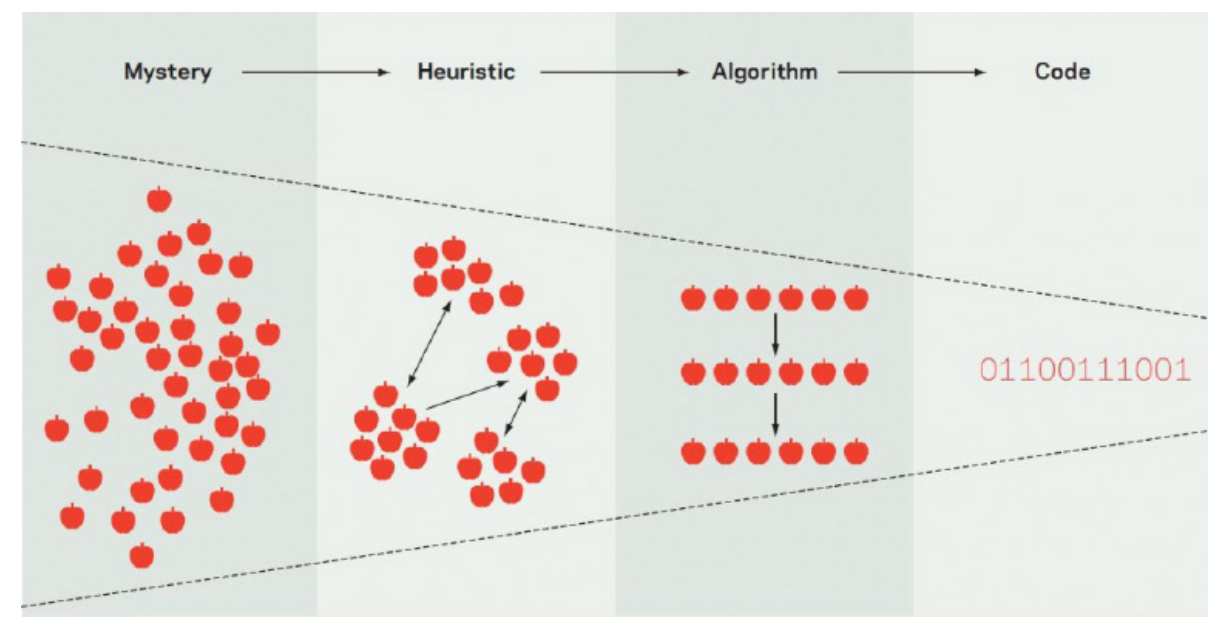

Fig. 12- O funil do conhecimento.

Fonte: MARTIN (2009), "The design of business: why design thinking is the next competitive advantage".

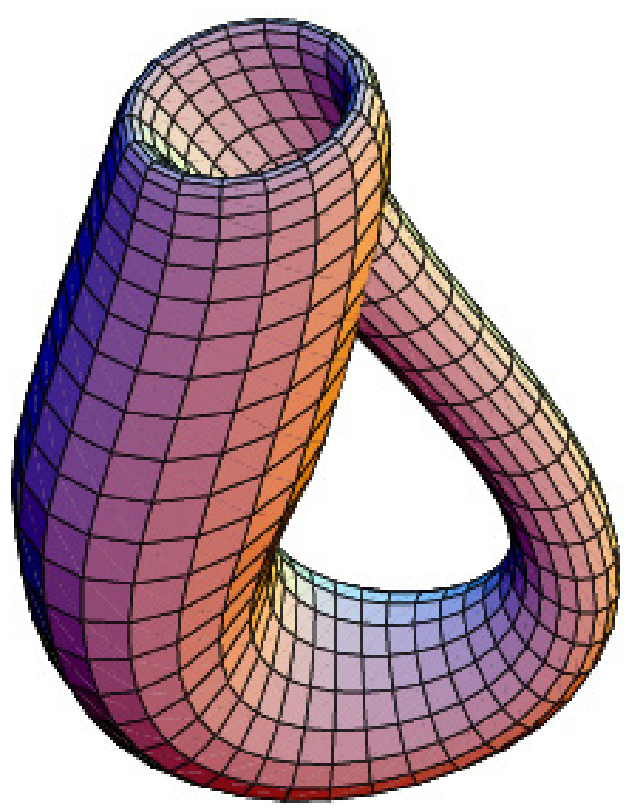

Fig. 12- Ergonomia de Futuro e a Garrafa de Klein 


\section{Considerações finais}

Não somos seres humanos vivendo uma experiência espiritual, somos seres espirituais vivendo uma experiência humana. (Teilhard Chardin) ${ }^{\mathbf{1 2}}$

Segundo Roger Martin, estamos imersos em mistério. O homem no mundo é o mistério sobre o qual se debruçam os Ergonomistas.

Usamos nossos diferentes tipos de raciocínio para extrair desse mistério, heurísticas.

Heurísticas são regras que usualmente funcionam, mas não em todas as circunstâncias. Talvez essa seja a principal diferença de uma Ergonomia preocupada com regras (nomos) e uma Ergonomia centrada no ser humano (ergon - prazer).

Algoritmos são prescrições para resolver um dado problema. Existem regras que precisam ser estabelecidas, mas é preciso ir muito além delas.

A educação do passado depositava algoritmos nas mentes dos alunos, verdades transmitidas de geração para geração. Erros que o cozimento do tempo nos faz crer que sejam verdades, dizia Gilles Deleuze.

A educação do futuro trabalha com as incertezas, aprende sobre o mistério e nos ensina a amá-lo e

não mais temê-lo. Transforma cada trabalhador em uma metamorfose ambulante que cria mundos e se recria no processo.

É uma Ergonomia viva que se ajusta aos tempos e respeita as diferentes culturas. É uma estrada sem começo e sem fim, só caminho.

Figura 11 - Ergonomia de Futuro e a Garrafa de Klein

A figura 11 mostra uma garrafa de Klein, que é obtida pela colagem de duas fitas de Moebius. A fita de Moebius é uma superfície unilateral. Lacan a utilizava para falar da continuidade entre consciente e inconsciente. Usamos a fita, aqui, para falar da parte visível e invisível da Ergonomia. Análise da Demanda consiste nisso em tentar tornar visível o que está oculto.

A garrafa de Klein não possui bordas, esquerda ou direita, dentro e fora. Trata-se de um contínuo que se abre para o infinito, como a Ergonomia sobre a qual estamos falando aqui, a tentativa, condenada ao fracasso, de satisfazer um ser humano que, sabemos, é insaciável

É óbvio que se torna urgente não uma nova pedagogia, mas tantas pedagogias quantas forem necessárias para criarmos uma geração de Ergonomistas comprometidos em construir tantos mundos quantos sejam necessários para que as pessoas possam realizar o projeto infinito e inacabado que são: Afinal, somos mistério em busca de significado.

\section{Referências}

BLAICH. Ergodesign. (1997). In: Behaviour and Information Technology. London. Taylor and Frances.

BROWN, T. Design Thinking. Uma Metodologia Poderosa para decretr o fim de velhas ideias. Campus Editora. 
BUARQUE, Lia. (1996). Aspectos perceptivos da interação homem-computador. Workshop Brasil França. Universidade Federal de Santa Catarina,

CHAPANIS, A. (1965). Man-M\$achine Engineering. Belmont: Wadsworth.

CHAPANIS, A. (1972). A engenharia e o relacionamento homem-máquina. São Paulo, Atlas.

CHARDIN, Teilhard de. (1971). El fenomeno humano. Barcelona, Taurus, p. 383

CHARDIN, Teilhard de. (1959). L'Avenir de L'Homme (406 p). Paris, Seuil.

CREMA, Roberto; LELOUP, Jean-Yves; Weil, Pierre; org. por Suzana Beiro. (2003.) Normose - $a$ patologia da normalidade. Vozes Editora.

CUNHA FILHO, José Leão. A certeza da incerteza educa. http://www.humanitates.ucb.br/3/ certeza.htm

CYBIS, Walter de Abreu. (1996). Modelo de objetos de interação abstratos ergonômicos:

desenvolvimento e perspectivas. Workshop Brasil França. Universidade Federal de Santa Catarina.

DETIENE, Françoise. (1996).A concepção e a reutilização de software: abordagem ergonômica. Workshop Brasil França. Universidade Federal de Santa Catarina.

DUL, J. \& WEERDMEESTER, B. (1995). Ergonomia Prática. São Paulo, Edgard Blucher.

FANN, K. T. (1970). Peirce's theory of abduction. The Hague: Martinus Nijhoff.

FIALHO, F. \& CYBIS. (1995). Alice-Uma Abordagem Eco-Ergonômica para a Utilização do Espaço (p. 595-60o).- In: ANAIS III Encontro Nacional -Latinoamericano de Conforto no Ambiente Construído, Gramado, R. S. ANTAC, Ju.

FIALHO, F. A. P. (2001). Ciências da Cognição (v.100o. p.263). Florianópolis: Editora Insular.

FIALHO, F. A. P. (2011). Psicologia das Atividades Mentais (v.100o. p.344). Florianópolis: Editora Insular,

FIALHO, F. A. P., SANTOS. (1995). Neri dos. Manual de Análise Ergonômica do Trabalho (v.2000, p.283) . Curitiba: Gênesis Editora. Este livro teve sua segunda edição em 1997, v. 1000, p.316.

FIALHO, F. A. P., SANTOS, Neri dos; PROENCA, R., DIAS, C. R. R. A. R. (1997) ANTROPOTECNOLOGIA: A ERGONOMIA DAS ORGANIZACOES (, v.100o. p.320.). CURITIBA: GENESIS.

FIALHO, Francisco A. P.(1996). Organizações, velhas metáforas e novas ideias. Workshop Brasil França. Universidade Federal de Santa Catarina. 
FREIRE, P. (2005). A importância do ato de ler em três artigos que se completam. São Paulo: Cortez.

GHIZZI, E. B. (2010). Arquitetura em diagramas: uma análise da presença do raciocínio dedutivo-diagramático no processo projetivo em arquitetura (v. 3, n. 2, p. 109-124, jul.- dez. 2006). Cognitio-Estudos, São Paulo. Disponível em: http://www4.pucsp.br/pos/filosofia/ Pragmatismo/cognitio estudos/cognitio estudos.htm Acesso em: 21 ago.

GRANDJEAN, Etienne. (1969). Précis d'ergonomie. Paris: Dunod,

GRANDJEAN, Etienne. (1988). Fitting the Task to the Man - An Ergonomic Approach. London, Taylor \& Francis.

GUILlEVIC, Christian. (2002). Psychologiedu travail. Presses universitaires de France, Paris.

GUATTARI, Félix. (1990). As três Ecologias. São Paulo: Papirus Editora,

IIDA, Itiro; BUARQUE, Lia. (2016). Ergonomia Projeto e Produção (; $3^{\mathrm{a}}$ edição. p. 856). Edgard Blucher Editora

LAVE, Jean. WENGER, Etienne (1991). Situated Learning: Legitimate Peripheral Participation. Cambridge: Cambridge University Press. ISBN 0-521-42374-0.; first published in 1990 as Institute for Research on Learning report 90-0013

MARTIN, Roger L. (2009). "The design of business: why design thinking is the next competitive advantage".

MATURANA, Humberto y VARELA, Francisco. (1997). De máquinas e seres vivos. Autopoiese, a Organização do Vivo. Porto Alegre: Artes Médicas.

MATURANA, Humberto. (2001). A árvore do conhecimento: as bases biológicas da compreensão humana. São Paulo: Palas Athena.

MATURANA, Humberto, VERDEN-ZOLLER, Gerda e BRUNNELL, Pille. (2009). The Origins of Humanness in the Biology of Love. Paperback.

MONTMOLLIN, Maurice du. (1986). L'Ergonomie. Paris, La Découverte.

MORAES, A. de \& SOARES, M.M. (1989) Ergonomia no Brasil e no mundo: um quadro, uma fotografia. Rio de Janeiro, Univerta/Abergo.

MORAES, A. FRISONI, B. C. (2000). Ergodesign: produtos e processos (208 p). Rio de Janeiro: $2 \mathrm{AB}$.

MORIN, Edgar. (1962). L'esprit du temps, Grasset, Paris. Em português: Cultura de Massa no século XX - O espírito do tempo. 
PEIRCE, C. S. The collected papers of Charles Sanders Peirce. Ed. de C. Hartshorne; P. Weiss \& A. W. Burks. Cambridge, Harvard University Press, 1931-1958. 8 v. (CP).

. The essential Peirce: selected philosophical works. Ed. de N. Houser et al. Bloomington, Indiana University Press, 1992. 2 v. . Semiótica. Trad. de J. T. Coelho Neto. São Paulo, Perspectiva, 2000. (Coleção Estudos, 46).

RAMOS, Edla Maria Faust Ramos. Análise ergonômica do sistema hiperNet buscando o aprendizado da cooperação e da autonomia. (1992-1996). 1996. 295 p. Tese(Doutorado em Engenharia de Produção) - UFSC, Florianópolis.

RICHARD, Jean Fraçois. (1990). Les activités mentales. Comprendre, raisonner, trouver des solutions. Paris: Armand Colin.

RICHARD, Jean François. (1996). Ferramentas para analisar e melhorar a compreensão das tarefas técnicas. Workshop Brasil França. Universidade Federal de Santa Catarina.

ROBERT, Jean Marc. (1996). Questões Relacionadas a Tarefa no Projeto da Interação HomemComputador. Workshop Brasil França. Universidade Federal de Santa Catarina.

SANTAELLA, L. (2004). O método anticartesiano de C. S. Peirce. São Paulo: Editora UNESP.

SANTOS, Neri dos. (1996). Uma introdução à modelagem Ecoergonômica. Workshop Brasil França. Universidade Federal de Santa Catarina.

SCAPIN, Dominique (INRIA). (1996). Inspeção ergonômica de interfaces e critérios ergonômicos. Workshop Brasil França. Universidade Federal de Santa Catarina.

SCLIAR Cabral, Leonor. (1996). Acesso Lexical. Workshop Brasil França. Universidade Federal de Santa Catarina.

TEILHARD de Chardin, P. (1959). L'Avenir De L'Homme (p. 406). Paris, Seuil.

TEILHARD de Chardin, P. (1971). El fenomeno humano (p. 383). Barcelona, Taurus.

WENGER, E.. (1998). Communities of practice: learning, meaning, and identity. New York: Cambridge University Press.

WASLAWICK, Raul. (1996). Agentes autônomos e teoria de equilibração cognitiva. Workshop Brasil França. Universidade Federal de Santa Catarina.

WISNER, Alain. « Cognitive Psychology and Anthropology (V. I.1991)», (collected papers), Conservatoire national des arts et métiers, Paris, mimeo.

WISNER, A. (1987). Por Dentro do Trabalho: Ergonomia, Método e Técnica - São Paulo, FDT/Oboré. 